\title{
Determination of blood glucose using an oxidase- peroxidase system with a non-carcinogenic chromogen
}

\author{
P. TRINDER \\ Biochemistry Department, Central Laboratory, Royal Infirmary, Sunderland
}

SYNOPSIS Manual and automated methods for the determination of blood glucose have been devised using an oxidase/peroxidase system, with dl adrenaline, a non-carcinogen, as oxygen $\vec{G}$ acceptor. The manual technique employs a stable single solution protein precipitant and the other reagents used are also stable. The automated methods are operated at $40 / \mathrm{hr}$ sample speed and ${ }^{\circ}$ washover between samples, over a very wide concentration range, is negligible.

The Chester Beatty Institute for Cancer Research have recently issued a pamphlet (1966) recommending that where possible o-tolidine and related compounds should not be used. The most widely used oxidase methods for the determination of blood glucose employ the' reactions: glucose + glucose oxidase + oxygen $=$ gluconic acid $+\mathrm{H}_{2} \mathrm{O}_{2}$ and $\mathrm{H}_{2} \mathrm{O}_{2}+$ peroxidase + chromogen $=$ coloured product.

The chromogens most often used are o-tolidine and o-dianisidine, and an automated method using these had been performed in this laboratory for some time. A suitable non-carcinogenic chromogen was sought as a possible substitute for o-tolidine, and adrenaline which oxidizes to the red compound adrenochrome was examined.

Methods have been worked out for macro and micro automatic analysis and for manual use.

MANUAL METHOD

REAGENTS These are as follows

1 Protein precipitant Sodium tungstate $\mathrm{Na}_{2} \mathrm{WO}_{4}$ $2 \mathrm{H}_{2} 0,10 \mathrm{~g}, 10 \mathrm{~g}$ of $\mathrm{Na}_{2} \mathrm{HPO}_{4}$, and $9 \mathrm{~g}$ of $\mathrm{NaCl}$ are dissolved in $800 \mathrm{ml}$ of water. About $125 \mathrm{ml}$ of $\mathrm{N} \mathrm{HCl}$ is added to bring the $p \mathrm{H}$ to 3.0 (narrow range paper).

The mixture is made up to 1 litre with water. It keeps for at least six months at room temperature.

$20.5 \% \mathrm{w} / \mathrm{v}$ dl adrenaline in $0.5 \mathrm{~N} \mathrm{HCl}$ Keeps for at least six months at $4^{\circ} \mathrm{C}$.

$30.1 \%$ w/v peroxidase R.Z. 0.6 Keeps for at least 14 days at $4^{\circ} \mathrm{C}$.

4 Colour reagent One hundred $\mathrm{ml}$ of $40 \% \mathrm{w} / \mathrm{v}$ sodium acetate $\mathrm{CH}_{3} \mathrm{COONa} 3 \mathrm{H}_{2} \mathrm{O}+10 \mathrm{ml}$ of Fermcozyme 653

Received for publication 27 June 1968
$\mathrm{AM}+10 \mathrm{ml}$ of $0 \cdot 1 \%$ peroxidase. Keeps for at least six $\vec{\varphi}$ months at $4^{\circ} \mathrm{C}$.

5 Glucose standards These are made up as $0-1,000 \mathrm{mg} /$ $100 \mathrm{ml}$ in $0.2 \% \mathrm{w} / \mathrm{v}$ benzoic acid.

PROCEDURE Blood, $0.1 \mathrm{ml}$, is added to $2.9 \mathrm{ml}$ of protein precipitant contained in a $\frac{5}{8}$ in. cylindrical centrifuge tube. After centrifugation at $2,000 \mathrm{~g}$ for five minutes, $\stackrel{\mathbb{\Omega}}{\Omega}$ $2.5 \mathrm{ml}$ of clear supernatant fluid is transferred to a $\frac{5}{8}$ in. $\Rightarrow$ tube labelled $U$. In two $\frac{5}{8}$ in. tubes labelled $S$ and $B$, $2.9 \mathrm{ml}$ of protein precipitant is placed. To tube $\mathrm{B}, 0.1 \mathrm{ml}$ of water is added; to tube $S, 0.1 \mathrm{ml}$ of a standard con taining $200 \mathrm{mg}$ of glucose $/ 100 \mathrm{ml}$ is added. Then $0.5 \mathrm{ml}$ of $0.5 \%$ adrenaline and $0.5 \mathrm{ml}$ of colour reagent ares added to tube $U$ and $0.6 \mathrm{ml}$ quantities of these solutions: are added to tubes $\mathbf{S}$ and $B$. The three tubes are mechanically shaken for $\mathbf{4 0}$ minutes. A Unicam SP $\mathbf{5 0 0}$ spectrophotometer is set with B and the optical densities of $U$ and $S$ are read at $500 \mathrm{~m} \mu$, using $10 \mathrm{~mm}$ cells.

$$
\text { Blood glucose }(\mathrm{mg} / 100 \mathrm{ml})=\frac{\text { O.D. } \mathrm{U}}{\text { O.D. } \mathrm{S}} \times 200
$$

Beer's law is strictly obeyed up to an optical density of $1 \cdot 0$, and there is only a slight deviation up to O.D. $1.5 \mathrm{O}$ (Table I).

If greater sensitivity is required, $0.2 \mathrm{ml}$ of the sam

T ABLE I

DATA FOR CALIBRATION GRAPH ${ }^{1}$

\begin{tabular}{cr} 
Glucose $(\mathrm{mg} / 100 \mathrm{ml})$ & Optical De \\
\hline 0 & 0.000 \\
50 & $0 \cdot 105$ \\
100 & 0.209 \\
200 & 0.412 \\
400 & 0.825 \\
1000 & 1.980
\end{tabular}

${ }^{1}$ Final volume of sample $4.2 \mathrm{ml}$. 
ple is used with $2.8 \mathrm{ml}$ of the protein precipitant and the appropriate factor is used in the calculation. Occasionally a slight turbidity appears in the solutions. This has very little effect on the results but for very accurate work it is advisable to centrifuge the tubes before taking readings.

Sodium fluoride, $5 \mathrm{mg} / \mathrm{ml}$ of blood, has no effect on the readings.

\section{AUTOMATED METHODS}

REAGENTS For the macro method use venous blood containing $1 \mathrm{mg} \mathrm{NaF}, 2 \mathrm{mg}(\mathrm{COOK})_{2} . \mathrm{H}_{2} \mathrm{O} / \mathrm{ml}$.

6 Diluent 3\% w/v $\mathrm{CH}_{3} \mathrm{COONa} .3 \mathrm{H}_{2} \mathrm{O} ; 0.5 \% \mathrm{w} / \mathrm{v}$ $\mathrm{MgSO}_{4} \cdot 7 \mathrm{H}_{2} \mathrm{O} \cdot 0.5 \mathrm{ml}$ of Brij 35 (Technicon formula) is added per litre.

$70.05 \% w / v$ dl adrenaline in $0.2 \% w / v$ benzoic acid Keeps for 14 days at room temperature.

8 Colour reagent Five hundred $\mathrm{ml}$ of reagent $7+$ $5 \mathrm{ml}$ of Fermcozyme 653 AM $+5 \mathrm{ml}$ of reagent 3. Keeps for 24 hours at room temperature.

In the micro method for $1 / 10$ dilutions of blood in $0 \cdot 1 \% \mathrm{w} / \mathrm{v} \mathrm{NaF}: 0.2 \% \mathrm{w} / \mathrm{v}(\mathrm{COOK})_{2} \cdot \mathrm{H}_{2} \mathrm{O} ; 0.9 \% \mathrm{w} / \mathrm{v} \mathrm{NaCl}$. 9 Diluent As for the macro method.

$100 \cdot 1 \% w / v$ dl adrenaline in $0.2 \% w / v$ benzoic acid Keeps for 14 days at room temperature.

11 Colour reagent Of reagent $10,100 \mathrm{ml},+3 \mathrm{ml}$ of Fermcozyme $653 \mathrm{AM}+3 \mathrm{ml}$ of reagent 3 . Keeps for 24 hours at room temperature.

12 Standards 5 diluted $1 / 10$ in $0.1 \%$ w/v NaF: $0.9 \%$ $w / v \mathrm{NaCl}, 0 \cdot 2 \% \mathrm{w} / \mathrm{v}(\mathrm{COOK})_{2} \mathrm{H}_{2} \mathrm{O}$.

PROCEDURES Use the macro and micro manifolds shown in Figures 1 and 2. A.R. chemicals were used where available. The Fermcozyme 653 AM and peroxidase RZ 0.6 were obtained from Hughes and Hughes Limited, 12a High Street Brentwood, Essex. Only dl adrenaline, obtainable from the Sigma Chemical Co. Limited, 12 Lettice Street, London, SW6, will give a colour which obeys Beer's law strictly up to an OD of 1.0 in the manual method. (dl Adrenaline is now available from Hughes and Hughes Ltd.) L Adrenalines from other sources give some deviation from the law at optical densities over $\mathbf{0 . 5}$. The use of a calibration graph will eliminate any errors due to such behaviour but $\mathrm{L}$ adrenaline has been preferred for convenience.

\section{RESULTS AND COMMENTS}

MANUAL METHOD Recovery of glucose added to EDTA blood which had stood for 48 hours to allow of decomposition of preformed glucose is shown in Table II. The initial glucose level was nil

\section{TABLE II}

RECOVERY OF GLUCOSE ADDED TO BLOOD BY MANUAL METHOD

\begin{tabular}{ccc}
$\begin{array}{c}\text { Glucose Added } \\
(\text { mg/100 ml })\end{array}$ & $\begin{array}{c}\text { Glucose Found } \\
(\text { mg/100 ml })\end{array}$ & Recovery (\%) \\
\hline 0 & 0 & - \\
50 & $50 \cdot 5$ & 101 \\
100 & 101 & 101 \\
200 & 197 & $98 \cdot 5$ \\
400 & 400 & 100 \\
1000 & 1020 & 102
\end{tabular}

and recoveries were almost quantitative. Sodium fluoride, $5 \mathrm{mg} / \mathrm{ml}$ of blood, had no effect on the results. It has been reported that uric acid interferes with glucose oxidase methods (Henry, 1964), but the addition of $1 \mathrm{mg}$ uric acid/ml of blood had no effect on the recoveries.

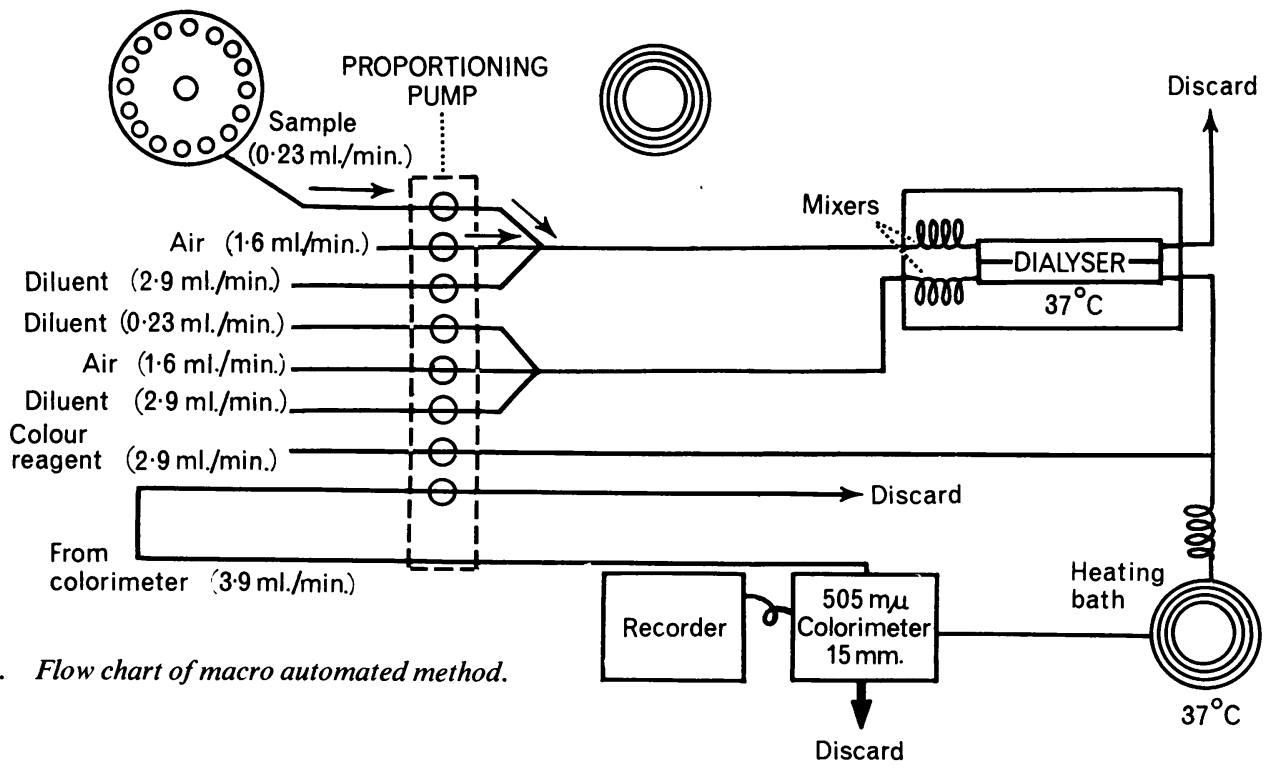




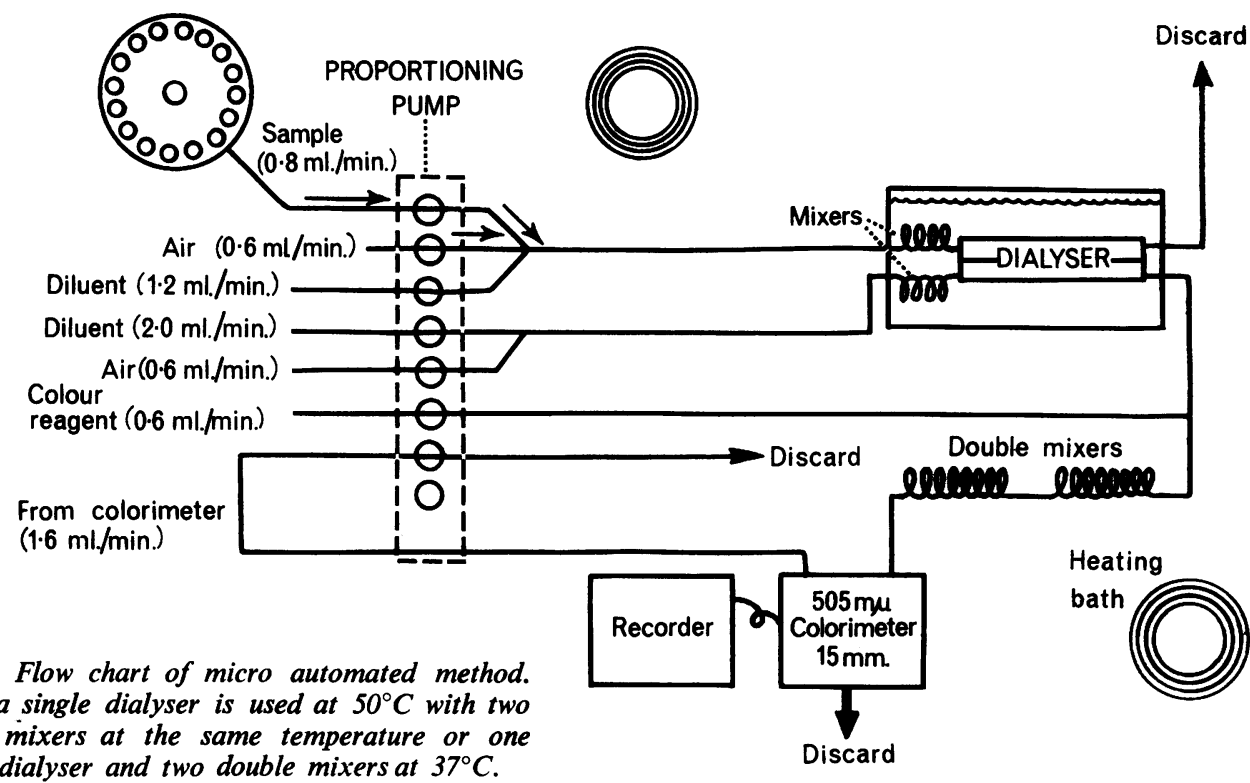

FIG. 2. Flow chart of micro automated method. Either a single dialyser is used at $50^{\circ} \mathrm{C}$ with two double mixers at the same temperature or one double dialyser and two double mixers at $37^{\circ} \mathrm{C}$.

FIG. 3. Typical recording of macro automated method. 
AUTOANALYZER METHODS At the 40/hour sampling rate, $1 \cdot 1$ wash ratio using a Pecker attachment to a sampler $\mathrm{I}$, the washover on analysing a sample containing $50 \mathrm{mg}$ glucose $/ 100 \mathrm{ml}$ following one containing $1,000 \mathrm{mg} / 100 \mathrm{ml}$ was negligible. The micro method is similarly insensitive to washover. Continuous samples on both macro and micro methods gave a horizontal straight line tracing which was only about one transmission line higher than a normal peak from the sample (Figs. 3 and 4). Recoveries of added glucose were similar to those obtained in the manual procedure.

The macro automated technique has been in continuous use for eight months and has proved very satisfactory. The micro automated procedure has been included here for workers who use a $1 / 10$ blood dilution as a routine, but it has not been in continuous use here.

The d1 adrenaline reaction was originally worked out for the AutoAnalyzer. The manual method was later included to give a method useful to all laboratories. Initially a two-solution technique was employed using trichloacetic acid/dl adrenaline to precipitate the proteins and sodium acetate/peroxidase/glucose oxidase to develop the colour. This method appeared to be satisfactory and recovery figures were excellent. However, when the method was being tried out in another laboratory, it was found that it gave consistently higher results than a copper reduction/phosphomolybdate method (Asatoor and King, 1954). This was due to the presence of a substance in erythrocytes which gave
TABLE III

COMPARISON OF RESULTS USING THREE METHODS ${ }^{1}$

\begin{tabular}{|c|c|c|c|}
\hline \multirow[b]{2}{*}{$\begin{array}{l}\text { No. of Blood } \\
\text { Specimens }\end{array}$} & \multicolumn{2}{|c|}{ Proposed Methods } & \multirow{2}{*}{$\begin{array}{l}\text { Arsenomolybdate } \\
\text { Method of King } \\
\text { and Garner (1947) }\end{array}$} \\
\hline & $\begin{array}{c}\text { Auto- } \\
\text { Analyzer }\end{array}$ & Manual & \\
\hline $\begin{array}{l}22 \\
44\end{array}$ & $111 \cdot 5$ & $\begin{array}{l}111 \cdot 1 \\
161 \cdot 2\end{array}$ & $\begin{array}{l}109 \cdot 3 \\
162 \cdot 3\end{array}$ \\
\hline
\end{tabular}

${ }^{1}$ Results are values expressed as $\mathrm{mg}$ glucose per $100 \mathrm{ml}$.

a colour with $\mathrm{dl}$ adrenaline/sodium acetate/peroxidase in the absence of glucose oxidase The technique given here eliminates this error but it is not so convenient as the original technique, which required the use of only two solutions and colour development was complete in 20 minutes. Further work is required to develop a more sensitive manual method.

I should like to thank Dr P. N. Coleman, consultant pathologist, Friarage Hospital, Northallerton, for pointing out the error in the original manual method. Thanks are also due to Dr R. A. M. Case, Professor of Social Medicine, Chester Beatty Research Institute, London, for guidance on the non-carcinogenic nature of adrenaline.

\section{REFERENCES}

Asatoor, A. M., and King, E. J. (1954). Biochem J., 56, xliv. Chester Beatty Research Institute (1966). Precautions for Laboratory Workers Who Handle Carcinogenic Aromatic Amines. Institute of Cancer Research, London.

Henry, R. J. (1964). Clinical Chemistry, Principles and Technics, p. 634. Hoeber, New York. (or repr., 1966).

King, E. J., and Garner, R. J. (1947). J. clin. Path., 1, 30. 